\title{
The Correlation of Narcissism and Selfie-Posting Behavior on Instagram among Millennials
}

\author{
Fadilla Andita Hernowo $^{1 *}$, Sri Fatmawati Mashoedi ${ }^{2}$ \\ ${ }^{1,2}$ Faculty of Psychology, University of Indonesia, Depok, Indonesia \\ *E-mail: fadilla.andita@ui.ac.id
}

\begin{abstract}
This research aims to find the correlation between narcissism and selfie-posting behavior on Instagram among Millennials. Millennials, those who were born between 1982 and 2004, known to be more selfish and low in empathy compared to the previous generation (Firestone, 2015) and they post their selfies more often (Pew Research Center, 2014). The narcissism variable is measured using Narcissism Personality Inventory 13 from Gentile et al. (2013) which has been translated into Indonesian language, meanwhile the selfie-posting behavior is measured using selfie-posting frequency in a month and Motivations for Posting Selfies on SNSs Scale (MPSS) from Sung et al. (2016) which also has been translated into Indonesian language. This research is being conducted to 443 young people aged between 16-24 who are active Instagram users in Indonesia. Based on the correlation test, there is a significant correlation between narcissism and selfie-posting behavior ( $\mathrm{r}=.187-.721)$, in which the higher one's score is in narcissism, the more selfies one takes.
\end{abstract}

Keywords: instagram; millennials; narcissism; selfie-posting; social media

\section{Introduction}

Instagram, as one of the most popular photo-based social media, ranked second as the most popular social media in Indonesia (Agrawal, 2015), with about 22 million active users in a month (Fajrina, 2016). Among all pictures posted on Instagram, the selfie is the most frequently uploaded photo $(\mathrm{Hu}$, Manikonda \& Kambhampati, 2014). The hashtag \#me and \#selfie were even ranked $2^{\text {nd }}$ and $6^{\text {th }}$, respectively, as the most used hashtags in Instagram (Hidayatullah, 2016). Compared to other cohorts, adolescents and young adults post selfie more frequently than the older generations (Dhir, Pallesen, Torsheim, \& Andreassen, 2016). A survey showed that about $55 \%$ of Millennials -individuals who were born between 1982 and 2004 - post their own selfies, which other generation tend not to (Pew Research Center, 2014). Millennials use selfies to show their identity and personal relationships, as well as to obtain positive responses from friends and acquaintances (Kim \& Chock, 2016).

At the same time, existing research suggests the increase of narcissism the last few decades, with Millennials having the highest narcissism scores, which is consistent with the stereotype of Millennials as "Generation Me" (Twenge \& Campbell, 2008). Even though the term "narcissism" refers to non-clinical narcissism, which is generally conceptualized as one's capacity to maintain a relatively positive self-image and seek out self-enhancement experiences from the social environment (Pincus, Ansell, Pimentel, Cain, Wright \& Levy, 2009), the reputation as narcissistic generation is often linked with more selfish and less empathetic attitude and behavior compared to the previous generations (Firestone, 2015).

Narcissism has received considerable attention in research examining psychological phenomena in SNS usage, especially narcissism with grandiose type (Ryan \& Xenos, 2011). Sorokowski, Sorokowska, Oleszkiewicz, Frackowiak, Huk \& Pisanski (2015) found that narcissism is correlated with the frequency of social media usage, and how one portrays oneself in online profile (Correa, Hinsley \& de Zuniga, 2010). With the easy access to advanced technology such as color filter, beauty editing, and photo-editing application from mobile phones, one can always enhance the physical appearance of their selfies. Furthermore, social media users have almost full control to freely curate the content they want to show to others in their social media profile (Buffardi \& Campbell, 2008).

Narcissism is not always pathological. Indeed, normal narcissism, also known as adaptive 
narcissism and social-personality narcissism, and pathological narcissism lie at different ends of the continuum (Miller \& Campbell, 2008). Normal narcissism contributes to self-esteem and well-being by increasing one's self-view (Oldham \& Morris, 1995 ) is associated with positive psychological wellbeing (Sedikies et al., 2004). Those who have high scores in normal narcissism, known as normal narcissists are motivated to gain attention and admiration from others to protect their own inflated self-view and think that they deserve privilege and special treatments (Fox \& Rooney, 2015; Morf \& Rhodewalt; 2001). One of the ways to attain that motivation is by posting a selfie on the most popular photo-based social media among Millennials (We Are Social, 2016).

Agrawal (2016) explained that social media narcissism is not a physical or mental disorder. However, even though most normal narcissists do not experience problems in daily life, the narcissism might affect individuals' relationship with others. For instance, individual who are high in their normal narcissism tend to be overly sensitive towards criticisms and evaluation by others, and also tend to blame others when experiencing failure, which then decreases the quality of interpersonal relationship quality (Panek, Nardis \& Konrath, 2013; Westerman, Bergman \& Daly, 2012). The increase in narcissism also causes people to keep doing selfenhancement and self-promotion about themselves, resulting inhibition to make a long-term relationship and therefore becomes a high risk for younger generation's psychological health (Panek et al., 2013).

Selfie-posting has become a way for people to explain about themselves (Ong et al., 2010). As a personal type of picture, selfie becomes a way for someone to communicate with others, sharing about one's whereabouts (Saltz, 2014). Oxford Dictionaries defined selfie as a photograph that one has taken of oneself, typically one taken with a smartphone or webcam or any digital camera, and shared via social media (Ozansoy Çadırcı \& Sağkaya Güngör, 2016). With that definition, the selfie is not just a photo that is taken in an arm-length distance but also includes any casual picture of one that is taken with a digital camera (Wright, 2013). Usually, selfies are enhanced using 'filter' by the owner before being uploaded to social media (Hess, 2015). The filter is used to create a modification in purpose to create better pictures for people to see them. With the access to such photo enhancement, selfies become the perfect media for people to create positive portrayals of themselves (Souza et al., 2015).
A few studies have examined the correlation between narcissism and selfie-posting behavior. Kim and Chock (2016) found that narcissism might be a strong predictor of selfie-posting behavior. Those who scored high in narcissism are more often to take pictures of themselves and post them in social media (Halpern, Valenzuela \& Katz, 2016; Lee \& Sung, 2016; Sorokowski et al., 2015). Sung et al. (2016) examined the correlation between narcissism and the motivation in posting selfies in SNS. He found attention seeking, communication, archive, and entertainment as four main motivations for people to post their selfies in social media. Narcissism correlates with all motivations, except archive. Social media provides a place for its users to seek acknowledgment and validation from others (Bazarova \& Choi, 2014). Those who are high in narcissism do not post their selfies for archiving, but for other people to see and to gain affirmation and validation from people who see that post (Ozansoy Çadırcı \& Sağkaya Güngör, 2016).

On the contrary, Wang, Yang, and Haigh (2017) found that narcissism was not directly correlated with selfie-posting behavior in Instagram. Instead, narcissism could only affect someone in posting selfies with a certain intention. Papadakis (2014) stated that those who posted their selfies more often had stronger need to gain attention from others instantly, and selfies were one of the fastest ways to fulfill the need. Posting selfies excessively to gain attention and satisfaction from others could also lead someone to get addicted to social media and it is also related with low self-esteem (Buffardi \& Campbell, 2008; Wang, Yang \& Haigh, 2017). Therefore, posting selfies could not be a motivationally vacuous activity; instead, it could be a form of selfexpression that carries with social and psychological meaning (Weiser, 2015).

This research aims to see the correlation between narcissism and selfie-posting behavior on Instagram among Millennials. Millennials are known to be more selfish and low in empathy compared to the previous generation (Firestone in Wickel, 2015) and they post their selfies more often (Pew Research Center, 2014). Given that narcissism is associated with selfie-posting behavior on SNS, it is expected that narcissism correlates with selfie-posting frequency. In addition, it is also expected that narcissism correlates with the motivations (attention-seeking, communication, and entertainment) behind selfieposting behavior on Instagram. Moreover, Wang, Yang, and Haigh (2017) found that narcissism was not immediately correlated with selfie-posting behavior in Instagram. Hence, further research needs to be done. 


\section{Methods}

Sample. A total of 443 adolescents and young adults or Millenials, those who were born between 1982 and 2004 (Mean age $=17.67, \mathrm{SD}=2.708$ ), Indonesians, $75 \%$ women, participated in this research. Questionnaires (online and offline) were given, followed by informed consent from each participant. All participants had to mention their own Instagram account to make sure that online and offline respondents are different.

Research Design. This study employed nonexperimental design. Participants were recruited using convenience sampling.

Instrument and Measurement. Narcissism is measured using Narcissism Personality Inventory 13 (NPI 13; Gentile, Miller, Hoffman, Reidy, Zeichner, \& Campbell, 2013). The obtained Cronbach's alpha reliability estimate for NPI 13 was high at .829. The only total score of NPI 13, consists of 13 items, was measured in this research. Both frequency and motivations for posting selfie are measured for selfie-posting behavior. Frequency is measured by measuring participants' selfie-posting frequency on Instagram in a month. Motivations (6 items for attention-seeking, 5 items for communication, and 4 items for entertainment) for posting selfies are measured using Motivations for Posting Selfies on SNSs Scale (MPSS; Sung et al., 2016). The obtained Cronbach's alpha reliability estimate for attention-seeking was .886, communication was .863 , and entertainment was .813 .

Procedure. NPI13 and MPSS were translated into the Indonesian language before given to participants by online and offline. Online questionnaires were posted on social media to gain more participants from every age group needed. Offline questionnaires were distributed in public and private high schools and universities in Jakarta, Indonesia. Data sampling was done on $3^{\text {rd }}-19^{\text {th }}$ of May 2017. The correlation of narcissism and selfie-posting frequency was processed using Kendall Tau-b Correlation. The correlation of narcissism and each motivation for posting selfie was processed using Pearson Correlation. All data were processed using IBM SPSS Statistics.

\section{Results}

There was no significant difference found in the narcissism scores between men and women, Instagram usage duration, and age. Selfie-posting behavior scores, including selfie-posting frequency and motivations in posting selfies (attention-seeking, communication, and entertainment) are also found not significantly different between gender $(\mathrm{p}=.230$ $.877)$, Instagram usage duration $(\mathrm{p}=.307-.881)$, and age $(\mathrm{p}=.087-.941)$. Thus, there is no significant difference in correlation of narcissism and selfieposting behavior between respondents' gender, Instagram usage, and age.

Table 1.

Descriptive Table of Narcissism and Selfie-Posting Behavior

\begin{tabular}{cccccc} 
& & \multicolumn{4}{c}{ Selfie-Posting Behavior } \\
\cline { 2 - 6 } - & Narcissism & $\begin{array}{c}\text { Freque } \\
\text { ncy }\end{array}$ & $\begin{array}{c}\text { Attention- } \\
\text { seeking }\end{array}$ & $\begin{array}{c}\text { Communica } \\
\text { tion }\end{array}$ & $\begin{array}{c}\text { Enter } \\
\text { tainm } \\
\text { ent }\end{array}$ \\
\hline & $\mathrm{M}=17.67$ & $\mathrm{M}=1.45$ & $\mathrm{M}=22.30$ & $\mathrm{M}=24.96$ & $\mathrm{M}=14.31$ \\
\hline is & $\mathrm{SD}=2,708$ & $\begin{array}{c}\mathrm{SD}=1.1 \\
01\end{array}$ & $\mathrm{SD}=7.930$ & $\mathrm{SD}=6.211$ & $\mathrm{SD}=4.397$ \\
\hline
\end{tabular}

NPI narcissism (13 items) is correlated positively with selfies posted per month. The higher narcissism score one has, the more selfies one posts on Instagram. Narcissism is also correlated with all motivations (6 items of attention-seeking, 5 items of communication, and 3 items of entertainment) in posting selfies.

Table 2.

Correlation of Narcissism and Selfie-Posting Behavior ( $p<.01$, one-tailed $)$

\begin{tabular}{ccccc}
\hline \multirow{2}{*}{ Narcissism } & \multicolumn{5}{c}{ Selfie-Posting Behavior } \\
\cline { 2 - 5 } & Frequency & $\begin{array}{c}\text { Attention- } \\
\text { seeking }\end{array}$ & $\begin{array}{c}\text { Communi } \\
\text { cation }\end{array}$ & $\begin{array}{c}\text { Entert } \\
\text { ainme } \\
\boldsymbol{n} \boldsymbol{n}\end{array}$ \\
\hline & $\mathrm{r}=.657$ & $\mathrm{r}=.721$ & $\mathrm{r}=.187$ & $\mathrm{r}=.257$ \\
\hline & $\mathrm{r}^{2}=.432$ & $\mathrm{r}^{2}=.519$ & $\mathrm{r}^{2}=.034$ & $\mathrm{r}_{=.0}^{2}$ \\
& & & & 66 \\
\hline
\end{tabular}

As seen in Table 1, there was a high correlation of narcissism with selfie-posting frequency and attention-seeking motivation. Participants tended to post selfies to gain attention from other people. In this study sample, social media narcissists uploaded more selfies than other to seek validation and attention from others about themselves. Communication was not correlated as high, perhaps because narcissists did not have the intention to engage in deep communication with others, as it was not their main motivation to post selfies. Narcissists also post selfies for entertainment purpose, which one may speculate for the psychological reward from receiving a positive response from others about their selfies. Age, gender and how long the participants own Instagram did not significantly affect the correlation. 


\section{Discussion \& Conclusion}

Discussion. This research supports the previous research concerning narcissism and SNS use. Narcissism score, measured using NPI 13 is correlated with selfie-posting frequency and motivations (attention-seeking, communication, and entertainment) in posting selfies (Kim \& Chock, 2016; Lee \& Sung, 2016). There was no significant difference found on narcissism score found between men and women in this research. This finding is consistent with Dhir (2016), who reported no significant difference in narcissism score between men and women. However, this result is contrary to Weiser's (2015) study, which found that the correlation between narcissism and selfie-posting frequency was higher in men, since men tend to post selfies to get recognition towards their leadership, showed by pictures they put on social media, while women tend to post their selfies purely to receive praise and acknowledgment from others. For future research, it is suggested to use each subscale in NPI 13 (leadership, grandiose, and entitlement) for better understanding concerning narcissism and its correlation with motivations in posting selfies. It is also suggested to consider self-esteem in selfieposting behavior. As Eşkisu, Hoşoğlu and Rasmussen (2017) found that self-esteem can affect someone's behavior in social media.

Conclusions. Narcissism is correlated with selfieposting frequency and three motivations (attentionseeking, communication, and entertainment) in posting selfies among Millennials. There is also no significant difference in correlation of narcissism and selfie-posting behavior between gender, age, and Instagram usage duration.

\section{References}

Agrawal, A. J. (August 3rd, 2016). 6 things to know about marketing to millennials. Forbes. Accessed from http://www.forbes.com/sites/ajagrawal/2016/08/03/6things-to-know-about-marketing-to-millennials/\#db6310a

Bazarova, N. N., \& Choi, Y. H. (2014). Self-disclosure in social media: Extending the functional approach to disclosure motivations and characteristics on social network sites. Journal of Communication, 64(4), 635-657

Buffardi, L. E., \& Campbell, W. K. (2008). Narcissism and social networking web sites. Personality and Social Psychology Bulletin, 34(10), $1303-$ 1314

Correa, T., Hinsley, A. W., \& De Zuniga, H. G. (2010). Who interacts on the Web?: The intersection of users' personality and social media use. Computers in Human Behavior, 26(2), 247-253

Dhir, A., Pallesen, S., Torsheim, T., \& Andreassen, C. S. (2016). Do age and gender differences exist in selfierelated behaviors? Computers in Human Behavior, 63 , 549-555
Eşkisu, M., Hoşoğlu, R., \& Rasmussen, K. (2017). An investigation of the relationship between Facebook usage, Big Five, self-esteem, and narcissism. Computers in Human Behavior, 69, 294-301

Fajrina, H. N. (June $27^{\text {th }}, 2016$ ). Ada 22 juta pengguna Aktif Instagram dari Indonesia. CNN Indonesia. Accessed from http://www.cnnindonesia.com/teknologi/20160623112758185-140353/ada-22-juta-pengguna-aktif-instagram-dariindonesia/

Firestone, L. (2012, October 15). Is social media to blame for the rise in narcissism? Huffington Post

Fox, J., \& Rooney, M. C. (2015). The dark triad and trait selfobjectification as predictors of men's use and selfpresentation behaviors on social networking sites. Personality and Individual Differences, 76, 161-165

Gentile, B., Miller, J. D., Hoffman, B. J., Reidy, D. E., Zeichner, A., \& Campbell, W. K. (2013). A test of two brief measures of grandiose narcissism: The Narcissistic Personality Inventory-13 and the Narcissistic Personality Inventory-16. Psychological assessment, 25(4), 1120

Halpern, D., Valenzuela, S., \& Katz, J. E. (2016). "Selfie-ists" or "Narci-selfies"?: A cross-lagged panel analysis of selfietaking and narcissism. Personality and Individual Differences, 97, 98-101

Hidayatullah, S. (September $8^{\text {th }}$, 2016). Pengguna Instagram Indonesia: suka late post dan selfie. Boomee. Accessed from http://boomee.co/lifestyle/pengguna-instagramindonesia-suka-latepost-dan-selfie/

Hess, A. (2015). Selfies, The selfie assemblage. International journal of communication, 9, 18

Hu, Y., Manikonda, L., \& Kambhampati, S. (2014). What we Instagram: The first analysis of Instagram photo content and user types. In Proceedings of the 8th International Conference on Weblogs and Social Media, ICWSM 2014, 595-598

Kim, J. W., \& Chock, T. M. (2016). Personality traits and psychological motivations predicting selfie posting behaviors on social networking sites. Telematics and Informatics, 34(5), 560-571

Lee, J. A., \& Sung, Y. (2016). Hide-and-seek: narcissism and "Selfie"-related behavior. Cyberpsychology, Behavior, and Social Networking, 19(5), 347-351

Miller, J. D., \& Campbell, W. K. (2008). Comparing clinical and social-personality conceptualizations of narcissism. Journal of Personality, 76(3), 449-476

Morf, C. C., \& Rhodewalt, F. (2001). Unraveling the paradoxes of narcissism: A dynamic self-regulatory processing model. Psychological Inquiry, 12(4), 177-196

Oldham, J. M., \& Morris, L. B. (1995). The new personality selfportrait: Why you think, work, love, and act the way you do. New York: Bantam Books

Ong, E. Y., Ang, R. P., Ho, J. C., Lim, J. C., Goh, D. H., Lee, C. S., \& Chua, A. Y. (2011). Narcissism, extraversion and adolescents' self-presentation on Facebook. Personality and individual differences, 50(2), 180-185

Ozansoy Çadırcı, T., \& Sağkaya Güngör, A. (2016). Love my selfie: selfies in managing impressions on social networks. Journal of Marketing Communications, 1-20

Panek, E. T., Nardis, Y., \& Konrath, S. (2013). Mirror or Megaphone?: How relationships between narcissism and social networking site use differ on Facebook and Twitter. Computers in Human Behavior29(5), 2004-2012

Papadakis, E. (July $\left.8^{\text {th }}, 2014\right)$. Selfies give instant gratification, take away memories. Move. Accessed from 
http://move.themaneater.com/stories/2014/7/8/selfies-giveinstant-gratification-take-away-memor/\#.WKFuaH9-BcJ

Pew Research Center (2014). Millennials in adulthood, detached from institutions, networked with friends. Accessed from http://www.pewsocialtrends.org/files/2014/03/2014-0307_generations-report-version-for-web.pdf

Pincus, A. L., Ansell, E. B., Pimentel, C. A., Cain, N. M. Wright, A. G. C., \& Levy, K. N. (2009). Initial construction and validation of the pathological narcissism inventory. Psychological Assessment, 21(3), 365-379

Ryan, T., \& Xenos, S. (2011). Who uses Facebook? An investigation into the relationship between the Big Five, shyness, narcissism, loneliness, and Facebook usage. Computers in Human Behavior, 27(5), 1658-1664

Saltz, J. (2014). Art at arm's length: A history of the selfie. New York Magazine, 47(2), 71-75

Sedikies, C., Rudich, E. A., Gregg, A. P., Kumashiro, M., \& Rusbult, C. (2004). Are normal narcissists psychologically healthy?: self-esteem matters. Journal of personality and social psychology, 87(3), 400-416

Sorokowski, P., Sorokowska, A., Oleszkiewicz, A., Frackowiak, T., Huk, A., \& Pisanski, K. (2015). Selfie posting behaviors are associated with narcissism among men. Personality and Individual Differences, 85, 123-127

Souza, F., de Las Casas, D., Flores, V., Youn, S., Cha, M., Quercia, D., \& Almeida, V. (2015, November). Dawn of the selfie era: The whos, wheres, and hows of selfies on Instagram. Proceedings of the 2015 ACM on conference on online social networks (pp. 221-231)
Sung, Y., Lee, J. A., Kim, E., \& Choi, S. M. (2016). Why we post selfies: Understanding motivations for posting pictures of oneself. Personality and Individual Differences, 97, 260-265

Twenge, J. M., \& Campbell, S. M. (2008). Generational differences in psychological traits and their impact on the workplace. Journal of Managerial Psychology, 23(8), 862877

Wang, R., Yang, F., \& Haigh, M. M. (2017). Let me take a selfie: exploring the psychological effects of posting and viewing selfies and groupies on social media. Telematics and Informatics, 34(4), 274-283

We Are Social. (2016). Digital In 2016. Accessed from www.wearesocial.com/uk/special-reports/digital-in-2016

Weiser, E. B. (2015). \# Me: Narcissism and its facets as predictors of selfie-posting frequency. Personality and Individual Differences, 86, 477-481

Westerman, J. W., Bergman, J. Z., Bergman, S. M., \& Daly, J. P. (2012). Are universities creating millennial narcissistic employees? An empirical examination of narcissism in business students and its implications. Journal of Management Education, 36(1), 5-32

Wilson, M., \& Gerber, L. E. (2008). How generational theory can improve teaching: Strategies for working with the "Millennials". Currents in teaching and learning, l(1), 2944

Wright, M. (June $27^{\text {th }}$ 2013). Peacocking Culture of Me: The Selfie Phenomenon. Medium. Accessed from https://medium.com/@macala/peacocking-culture-of-methe-selfie-phenomenon 